
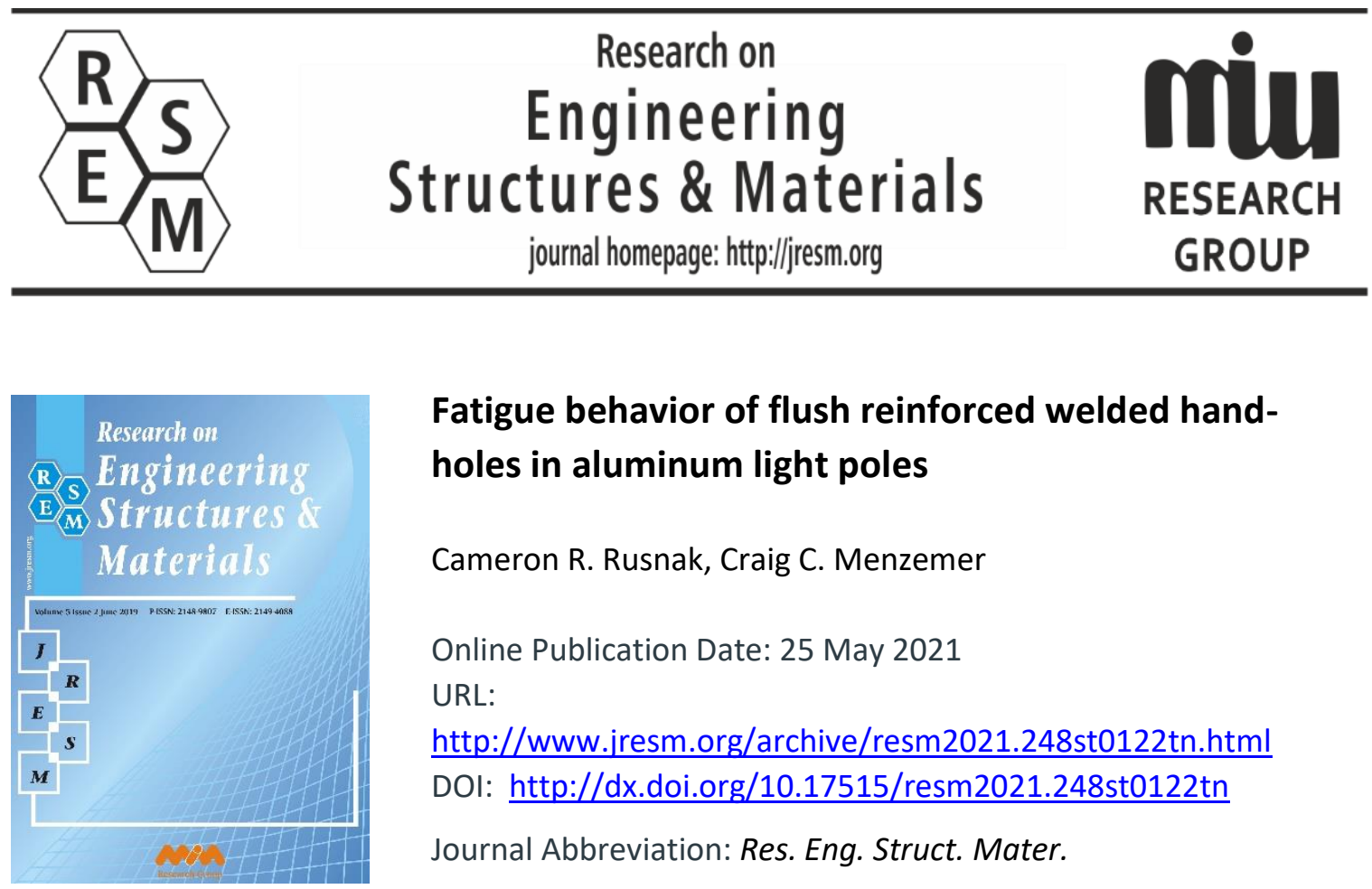

\title{
Fatigue behavior of flush reinforced welded hand- holes in aluminum light poles
}

\author{
Cameron R. Rusnak, Craig C. Menzemer \\ Online Publication Date: 25 May 2021 \\ URL:
}

http://www.jresm.org/archive/resm2021.248st0122tn.html DOI: http://dx.doi.org/10.17515/resm2021.248st0122tn

Journal Abbreviation: Res. Eng. Struct. Mater.

\section{To cite this article}

Rusnak CR, Menzemer CC. Fatigue behavior of flush reinforced welded hand-holes in aluminum light poles. Res. Eng. Struct. Mater., 2021; 7(3) 465-480.

\section{Disclaimer}

All the opinions and statements expressed in the papers are on the responsibility of author(s) and are not to be regarded as those of the journal of Research on Engineering Structures and Materials (RESM) organization or related parties. The publishers make no warranty, explicit or implied, or make any representation with respect to the contents of any article will be complete or accurate or up to date. The accuracy of any instructions, equations, or other information should be independently verified. The publisher and related parties shall not be liable for any loss, actions, claims, proceedings, demand or costs or damages whatsoever or howsoever caused arising directly or indirectly in connection with use of the information given in the journal or related means.

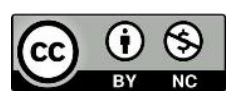

Published articles are freely available to users under the terms of Creative Commons Attribution - NonCommercial 4.0 International Public License, as currently displayed at here (the "CC BY - NC"). 


\title{
Research on Engineering Structures \& Materials
}

journal homepage: http://jresm.org

Technical Note

\section{Fatigue behavior of flush reinforced welded hand-holes in aluminum light poles}

\author{
Cameron R. Rusnak ${ }^{*}$, Craig C. Menzemer ${ }^{b}$
}

Auburn Science and Engineering Center (ASEC 210), Department of Civil Engineering, The University of Akron, Akron, Ohio, USA.

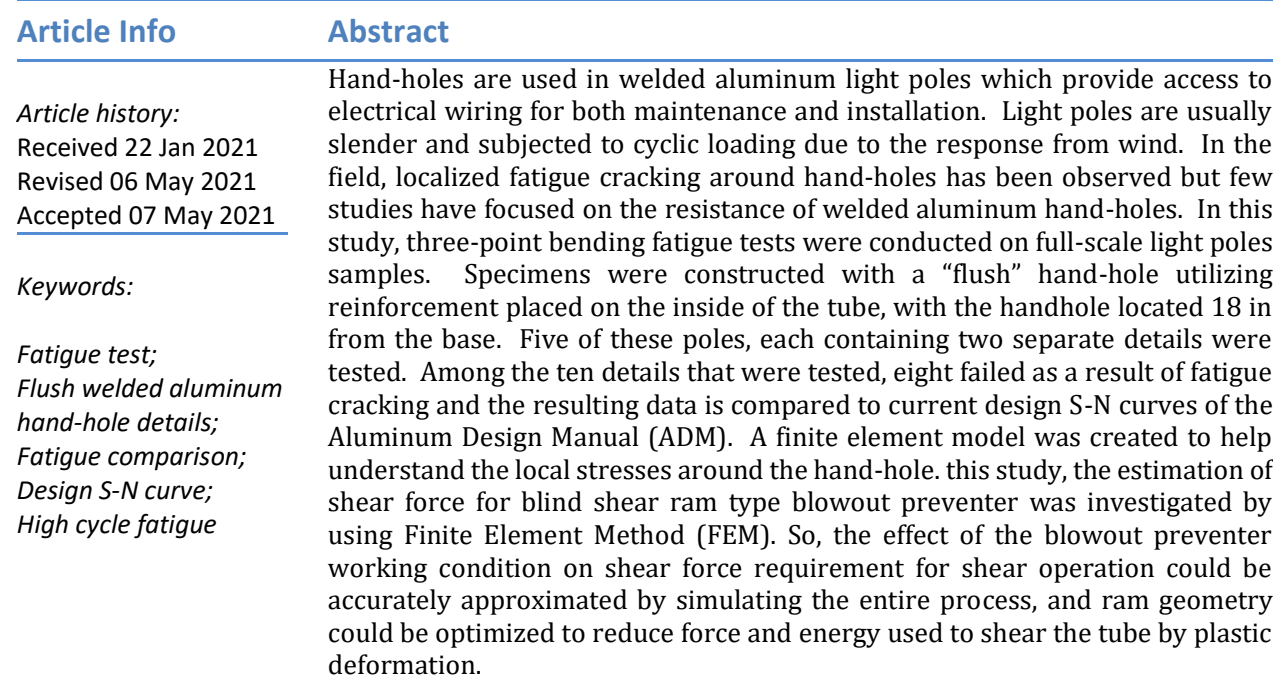

(C) 2021 MIM Research Group. All rights reserved.

\section{Introduction}

Overhead luminaires are often supported by welded aluminum light poles and serve to illuminate sidewalks, roadways, parking lots and recreational areas among others. The material used in these types of applications is often aluminum. Aluminum has several advantages, including being light weight, possessing a high strength to weight ratio, good corrosion resistance, as well as ease of joining. Light Poles may be classified as slender structures that are subjected to wind loads. Both aluminum and steel structures that are exposed to repeated loads may fail due to localized fatigue cracking. Light poles often contain a hand-hole that gives access for maintenance and connection of electrical wiring. Electrical wiring runs through conduit and into the open hollow section of the pole where final electrical connections are made with the luminaires [1,2].

Stress concentrations occur when there is a change in the cross-section of a structural member. A change in cross section may be associated with connections, copes, keyways, and cutouts among others. Modern fatigue design utilizes a statistically determined lower bound of data for design S-N curves, established from full-scale testing [3, 4]. A series of S$\mathrm{N}$ curves within specifications represent a ranking of the stress concentration condition and consist of common mechanical and structural details. A way to improve fatigue life is to eliminate low fatigue performance structural details and minimize changes in cross-

\footnotetext{
*Corresponding author: crr44@uakron.edu

a orcid.org/0000-0002-9048-594X; b orcid.org/0000-0002-6529-085X

DOI: http://dx.doi.org/10.17515/resm2021.248st0122tn

Res. Eng. Struct. Mat. Vol. 7 Iss. 3 (2021) 465-480
} 
section. There are several structural details of interest in welded aluminum light poles. These include mono-tube arm joints, the pole to base connection, and electrical access hand-holes. Previous studies have primarily focused on steel light pole details and their behavior is well established. This is not the case of electrical access holes in welded aluminum structures [5].

Web report, NCHRP number 176, provided results of fatigue tests of unreinforced and reinforced hand-holes in welded steel structures. Lehigh University conducted fatigue tests on details associated with high mast steel light poles. Thirteen specimens with handholes possessing different geometries were evaluated. During testing, none of the handhole details cracked [6]. To compliment the experiments, a finite element study was conducted and was used to provide an estimate of the stress concentration around the different hand-holes. The numerical analysis in combination with test results found that the fatigue resistance of both the reinforced and unreinforced hand-holes were consistent with AASHTO Category E' [6].

Fatigue cracking associated with hand-holes has been observed in the field. NCHRP report number 469 describes fatigue cracks that have occurred in welded steel structures near hand-hole details in multiple states. These include New York, New Mexico, California and Minnesota [7]. After the failure of a high-mast welded pole in Iowa, multiple inspections found cracks associated with a hand-hole at another location. Some fatigue cracks were found in welded aluminum light poles mounted on the Mullica River Bridge after a violent storm in New Jersey in 2011 [8]. A fatigue failure associated with a more typical (not flush) hand-hole reinforcement on an aluminum light pole can be seen in Figure 1.

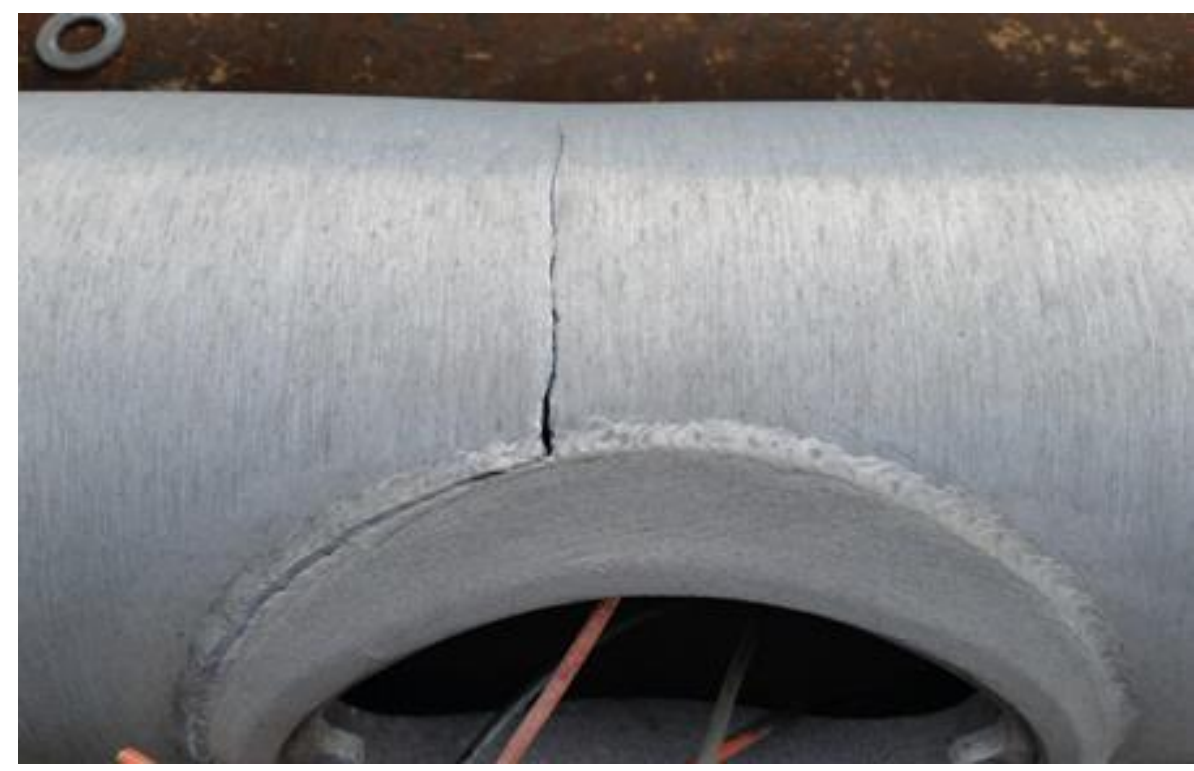

Fig. 1 Fatigue crack in welded aluminum light pole hand-hole in field

The University of Akron (UA) conducted a study on twenty light-pole samples with "typical" hand-holes containing the cast reinforcement shown in Figure 1. The cast reinforcement is joined to the outside of the poles with fillet welds. In addition to fatigue tests, several static tests were conducted in order to gain insight into the strain distribution around the hand-hole. This study found that typical reinforced welded hand-hole fatigue test data fell above both the category D and E design S-N curves of the Aluminum Design 
Manual (ADM) [9]. Another study found that the change in diameter of the pole has some effect on the fatigue life [10].

Taghipoor and Damghani Nouri found that an increase in the cell angle of sandwich beams with an expanded metal core, up to $\theta=90$ degrees, increased axial and bending energy absorption by $624.4 \%$. Numerical situations were also carried out using ABAQUS/EXPLCIT and the results were compared to the experimental data [11]. In a separate study, the same authors found that an increase in the size of the expanded metal cell core within a reasonable range improved the performance of a structure under bending collapse [12]. Tests of the sandwich beams were conducted in quasi-static three-point bending. Specific energy absorption of sandwich panels evaluated under axial impact was significantly improved by selection of an appropriate core [13].

During the current hand-hole fatigue study, five pole specimens, each containing two separate flush details were tested in high cycle fatigue. All poles were supplied to The University of Akron and were manufactured to standards typical for the industry. In addition to fatigue tests, a finite element model was created to aid in the understanding of the distribution of local stress around the handholes. The intention of this study was to examine the fatigue behavior of flush hand-hole details and to compare the results with previous work conducted at UA. In the field, "typical" reinforced hand holes are more common, but some prefer the flush insert design. The term "flush" denotes that the reinforcement is not visible from the outside. Rather the reinforcement is welded to the inside of the pole.

\section{Experiments and Methods}

\subsection{Pole Geometry and Material Properties}

Five aluminum specimens, with a total of ten details, were tested under cyclic loading to examine the fatigue behavior of the flush hand-holes. Each of the specimens were fabricated from 10 in $(25.4 \mathrm{~cm})$ diameter extruded 6063 aluminum alloy tubes with a $1 / 4$ in $(0.635 \mathrm{~cm})$ thick wall. Hand-holes measured 6 in $(15 \mathrm{~cm})$ in the longitudinal direction of the pole and 4 in $(100 \mathrm{~cm})$ in the transverse direction. Each hand-hole was reinforced on the inside of the pole with an extrusion that measured $9 \frac{1}{2}$ in $(24 \mathrm{~cm})$ in the longitudinal direction and 6.42 in $(16.3 \mathrm{~cm})$ in the transverse direction. Figure 2 depicts the design of this extrusion and Figure 3 shows the connection that uses longitudinal fillet welds to join the reinforcement extrusion to the inside of the pole around the hand-hole opening. The final samples measured 144 in (3.66 m) in length with the hand-holes placed 54 in $(1.37$ $\mathrm{m}$ ) in from each end respectively. Each specimen consisted of three separate pieces as shown in Figure 4. The central tube containing the hand holes measured 72 in $(183 \mathrm{~cm})$ in length and had pole bases welded on either end. Hand holes in the center pole section were located 18 in $(457 \mathrm{~cm})$ from either end which represents the largest distance a welder can comfortably work inside of the 10 in $(254 \mathrm{~cm})$ diameter tube. Stub poles measuring 36 in $(91 \mathrm{~cm})$ were welded to a base and bolted to the base on either end of the center section. The stub pole sections were designed to increase the moment arm from the point of specimen bearing to the hand hole. Support rollers for the specimens were placed 6 in $(15.2 \mathrm{~cm})$ from each end. All specimens were Post-Weld Heat Treated (PWHT) [14]. Table 1 provides properties of 6063 -T6 extrusions and the 4043-filler wire material. 

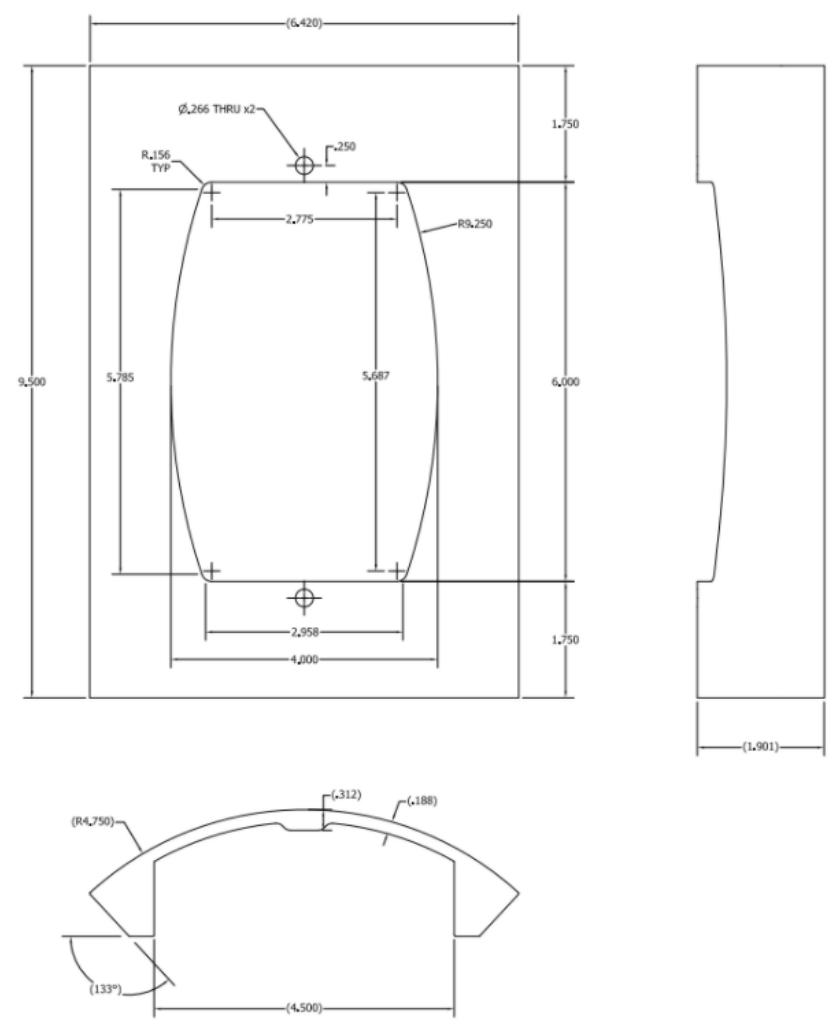

Fig. 2 Hand-hole reinforcement

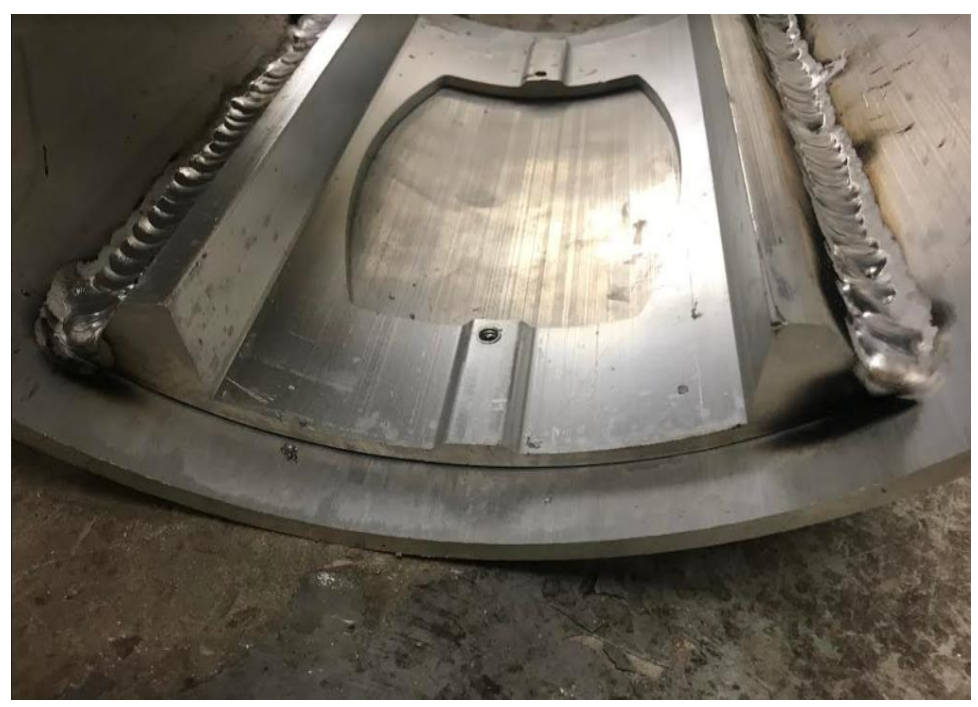

Fig. 3 Welded insert plate 


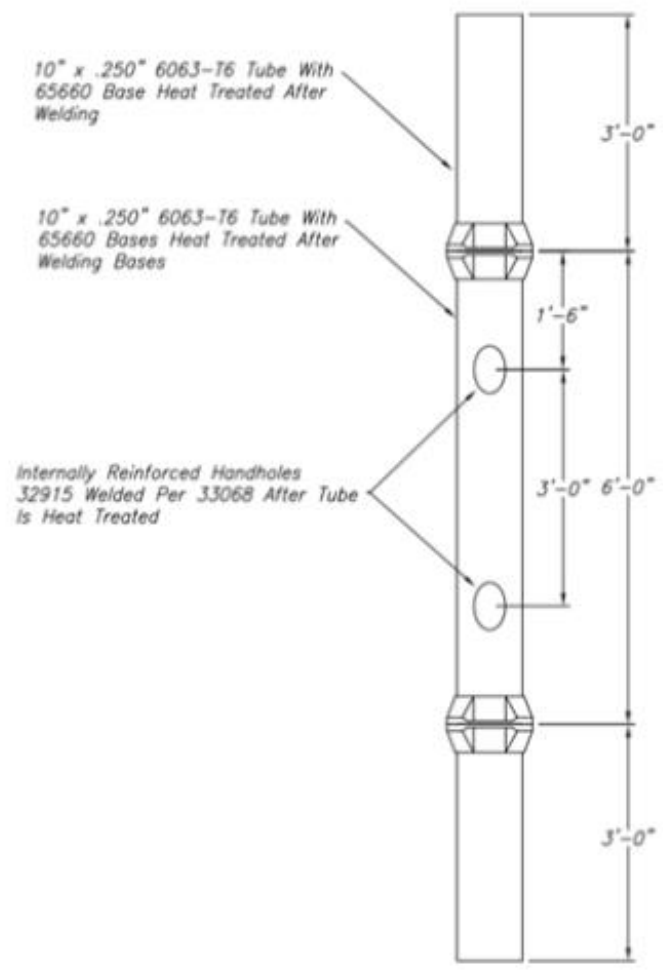

Fig. 4 Specimen design

Table 1 consists of the minimum mechanical properties of the aluminum and tube. Allowable bending strength of the tube used as a light pole is $13.6 \mathrm{ksi}$ (94 Mpa).

Table 1. Mechanical properties of the aluminum hand-hole tubes along with the filler material.

\begin{tabular}{cccc}
\hline Part Name & Alloy & Tensile Yield Strength & Ultimate Tensile Strength \\
\hline Tube & $6063-\mathrm{T} 6$ & $213.7 \mathrm{MPa}$ (31 ksi) & $241.3 \mathrm{MPa}$ (35 ksi) \\
Fillet Welding & 4043 & N/A & $201.3 \mathrm{MPa}$ (29.2 ksi) \\
\hline
\end{tabular}

\subsection{Fatigue Tests}

Figure 5 is a photograph of the three-point bending fatigue test setup in the Gas Turbine Testing Laboratory of The University of Akron. All of the earlier fatigue tests conducted at UA were in four-point bending. Three-point bending was used as the flush inserts were placed inside of the pole and limited the location of the hand hole to near the end of the specimens. Stub poles were added to increase the length and moment arm, but to ensure failure at the hand-hole required limiting the stress range at the base to tube connections. 
Three-point bending provided the means to limit the stress range at the base connections and ensure failure at the hand-hole details.

A 55 kip (245 KN) MTS servo-hydraulic actuator and control system was used to apply the load to specimens. This actuator was mounted to a structural load frame that is capable of safely supporting 300 kips (1335 KN). Loads were applied to each of the specimens through a roller that was attached to the actuator. Supports consisted of rollers that were machined to fit the profile of the tubular specimens.

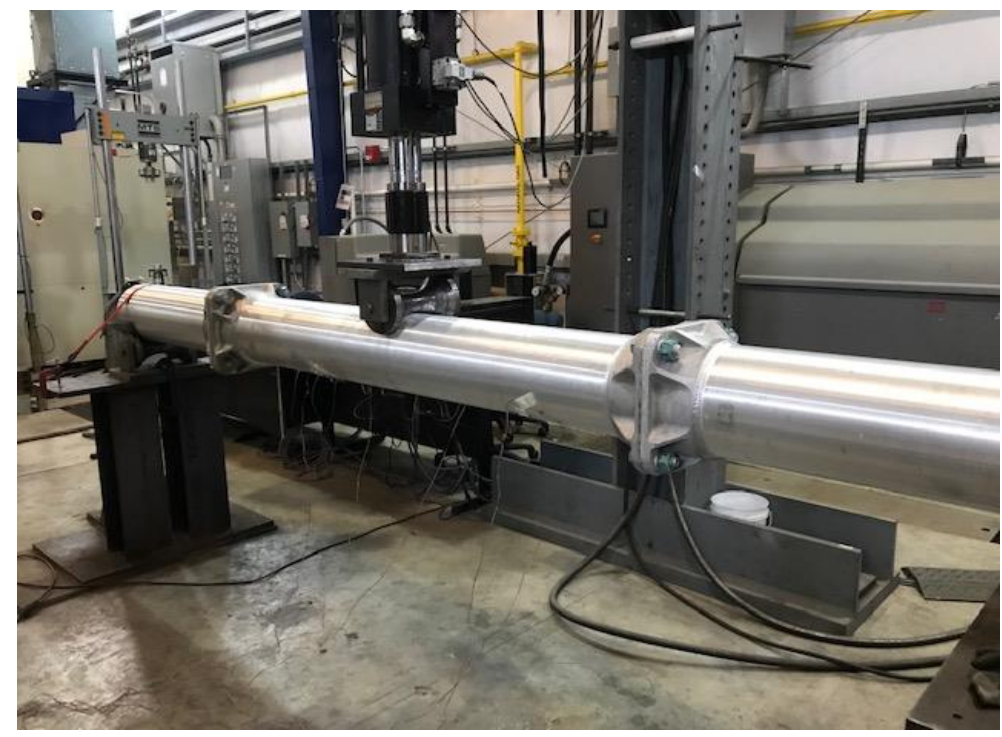

Fig. 5 Fatigue test set-up of flush welded aluminum hand-hole details

All the tests were conducted in load control, while strains were monitored using gages that were mounted around the hand-hole on the outside of the pole. Typical strain gage locations may be seen in Figure 6. On the first specimen tested, a strain gage was also placed at each 6 o'clock position and near each pole base respectively. Strain gages were $1 / 8$ in $(3.175 \mathrm{~mm})$ in length with a resistance of $350 \mathrm{ohms}$. Strain readings were taken every two hours for 10 seconds using a Micro-Measurements System 8000 data acquisition device.

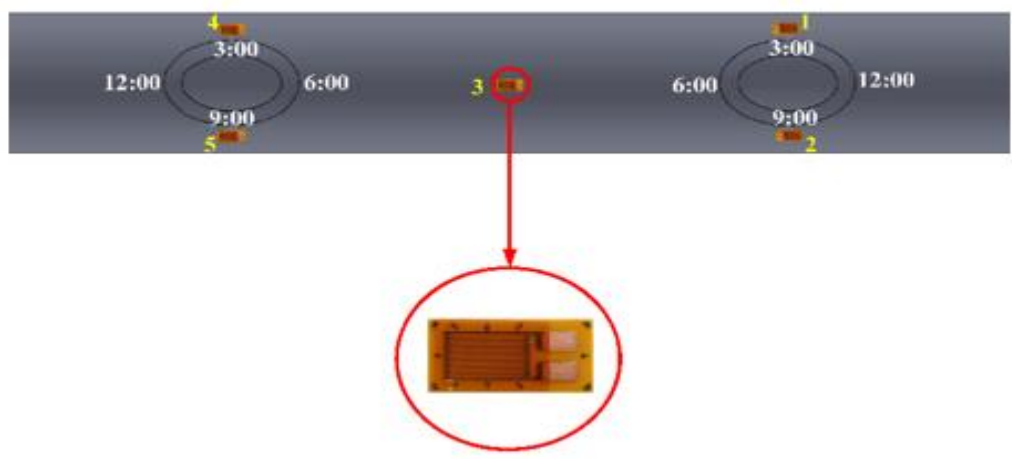

Fig. 6 Typical strain gage location and position around hand-hole 
Each of the specimens was oriented so that the hand-hole openings were facing down and in tension during cyclical testing. An over-peak displacement limit was set in an attempt to ensure that cracking of one hand-hole would not lead to catastrophic failure of the specimen. This over-peak limit was set to a $10 \%$ larger displacement from the original test parameters. The $10 \%$ limit was determined from a previous study [15]. As larger displacements were indicative of cracking and the remaining cross section was close to failure. When one of the two hand hole details of a sample experienced fatigue cracking, the specimen's displacement would increase. When the displacement became larger than the original target plus $10 \%$, the test would automatically shut down. After the first detail of the specimen failed, a moment clamp was placed on it for reinforcement. The test would then continue until the other hand-hole failed. The goal was to test the specimens and receive data from both details. Despite using the over-peak $10 \%$ detection limit, cracking around two hand-holes resulted in a catastrophic failure where the repair of the detail was not possible.

Five poles, each with two flush hand-hole details, were tested at a stress range between 14.2 $\mathrm{MPa}(2.06 \mathrm{ksi})$ and $49.6 \mathrm{MPa}(7.2 \mathrm{ksi})$. The stress ranges were determined by taking the strain range at the point of loading and then converting to stress. Young's modulus of elasticity for aluminum is well known and a simplified conversion to stress was taken as the strain multiplied by the modulus [16]. Strain gages were installed adjacent to the handhole at the 3 and 9 o'clock position respectively with an additional strain gage in the middle of the specimen on the extreme tension fiber. On the first two specimens tested, strain gages were also placed at the 6 o'clock (Figure 6) position. In general, gages around the hand holes were placed within $2 \sim 3$ times the tube thickness away from the edge of the hand-hole. Gages placed near the pole base were a thickness away from the weldment. All of the strain gages were connected to the data acquisition system to measure the strain during fatigue testing.

Specimens were cycled at either 1 or $2 \mathrm{~Hz}$ and tested around the clock. The difference between cycling at 1 and $2 \mathrm{~Hz}$ was negligible due to the size of the specimens and displacements in this study. It is generally accepted that corrosion fatigue is a rate limited process, and that the aluminum - water system is reactive. Differences in fatigue crack growth rates in aluminum under saturated water vapor conditions are not reaction rate dependent at low frequencies [17]. Specimens tested at a lower stress range were cycled at $2 \mathrm{~Hz}$ to decrease the time it took to conduct the test. Visual inspection of the hand-holes were conducted multiple times daily. Of the 10 hand-holes that were tested, 8 failed.

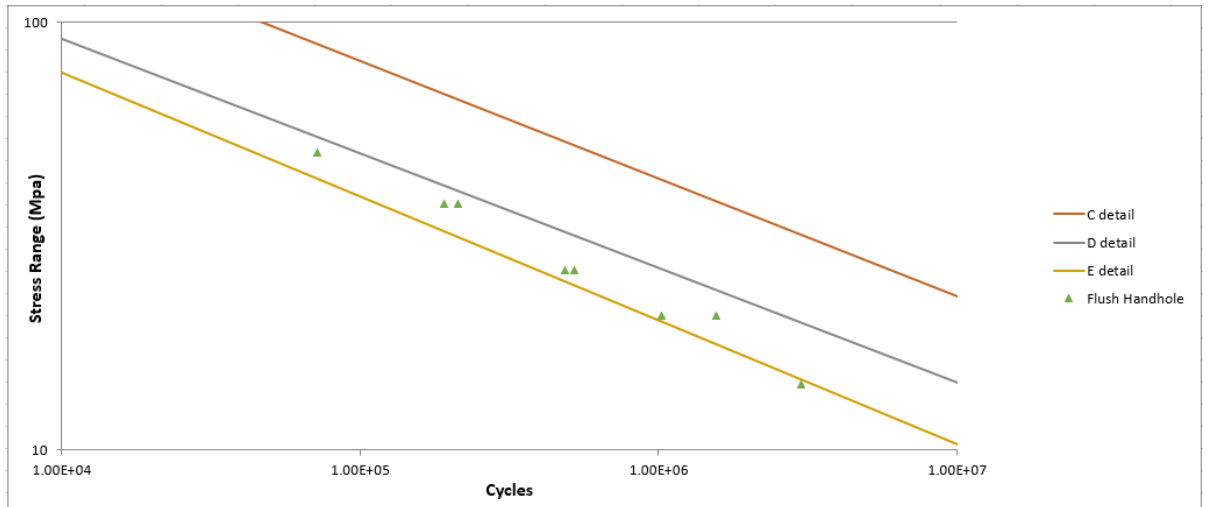

Fig. 7 Fatigue test results 
Table 2. Tabulated fatigue results

\begin{tabular}{ccccc}
\hline Specimen & Handhole & N & Stress Range (MPa) & Hertz \\
\hline 1 & A & 485225 & 26.37 & 1 \\
& B & 522967 & 26.37 & 1 \\
2 & A & 1558915 & 20.69 & 1 \\
& B & 1024092 & 20.69 & 1 \\
3 & A & 2990006 & 14.22 & 2 \\
& B & NA & 14.22 & 2 \\
4 & A & 191810 & 37.75 & 1 \\
& B & 213306 & 37.75 & 1 \\
5 & A & NA & 49.64 & 1 \\
& B & 71648 & 49.64 & 1 \\
\hline
\end{tabular}

The data collected from the fatigue tests can be seen in Figure 7 and tabulated results are available in Table 2 . The stress range in Table 2 was calculated by subtracting the minimum stress in an average load cycle from the maximum stress in the same cycle. All of the data appears to follow the same trend, slightly above the "E detail" lower bound. Figure 8 shows a comparison between the flush details and a previous study conducted on 10 in poles with a "typical" hand-hole detail. This figure shows that typical hand-hole details with reinforcement fillet welded to the outside of the tube (Figure 1) have a larger fatigue resistance as compared to flush hand-hole details.

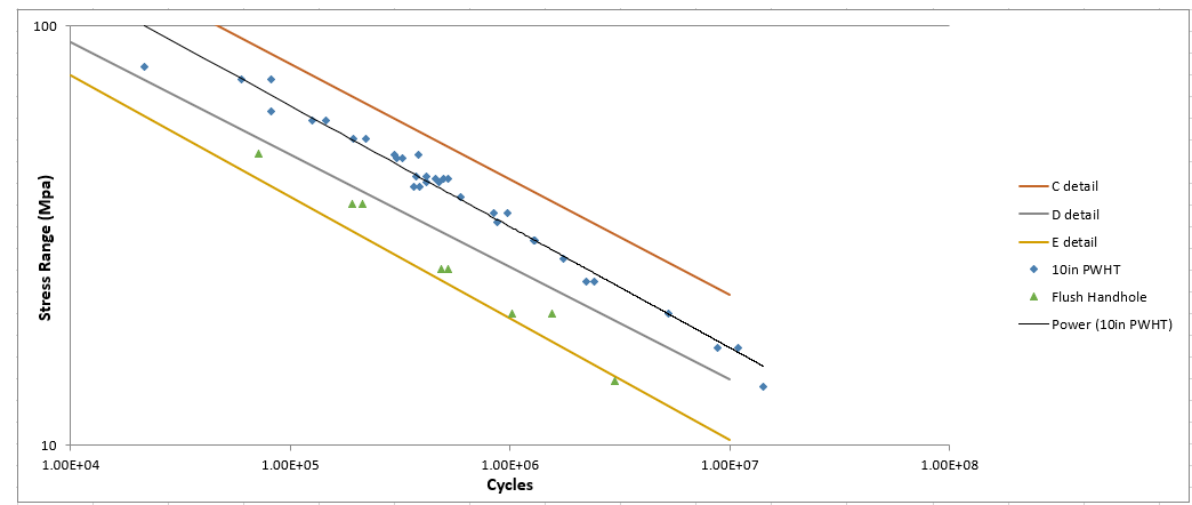

Fig. 8 Flush detail vs 10 in poles with standard hand-hole reinforcement

During fatigue testing, the appearance of cracking was soon followed by failure. After cutting open several failed specimens, it became apparent that the hand-holes experienced failure that initiated in the weld that joins the reinforcement extrusion to the inside of the pole (closer to the load). Figure 9 shows the nature of the crack on the inside of the pole and Figures 10 and 11 show the weld removed from the pole. These images show how "jagged" the break is after failure and how initiation appears to coincide with the fillet weld termination. Often, fillet weld terminations in aluminum will contain shrinkage defects unless properly "buttoned up". 


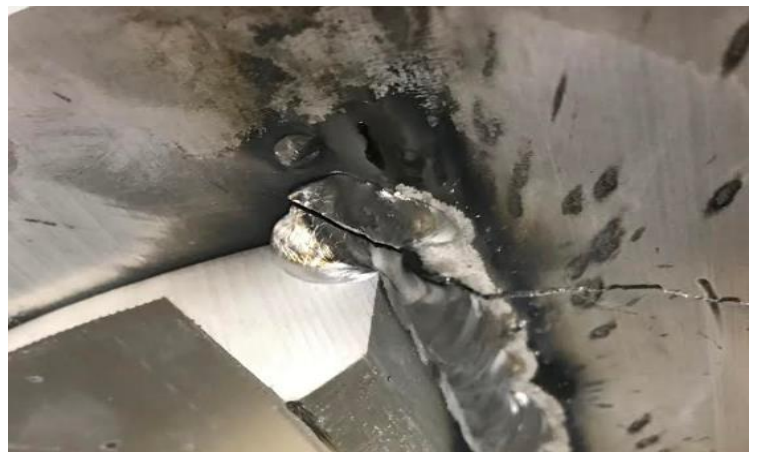

Fig. 9 Crack in weld

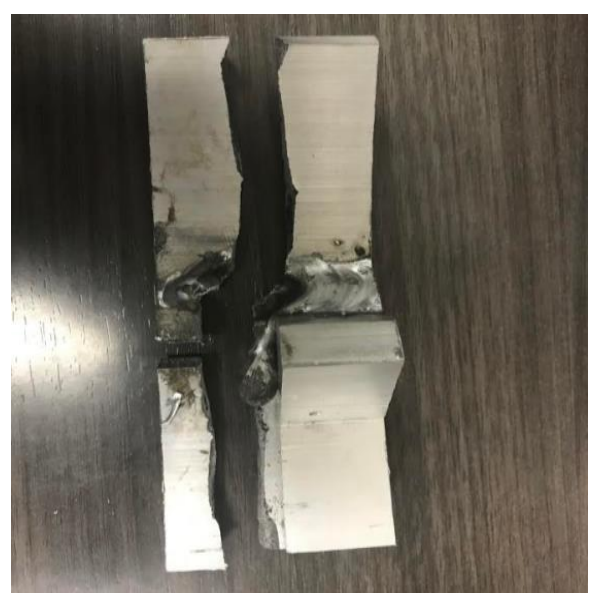

Fig. 10 Weld failure location

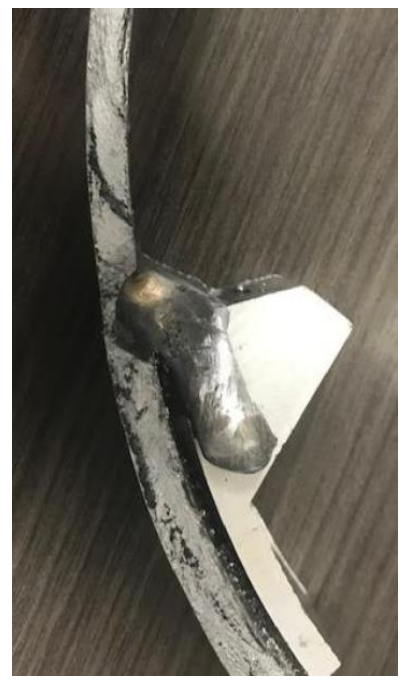

Fig. 11 Failure of pole sample 
Final failure occurred as the crack broke though the surface of the tube, usually at the 6 o'clock position and propagated transversely in the pole until the displacement limit was reached and the test was stopped. In all of the specimens, initial cracking could not be observed due to the detail being inside of the pole. Figure 12 depicts a typical final failure. A few of the specimens contained a smaller crack, at about the 4 o'clock position. This still followed the same failure mode with the crack initiating within the weldment inside of the pole. Figure 13 shows an example of this type of cracking.

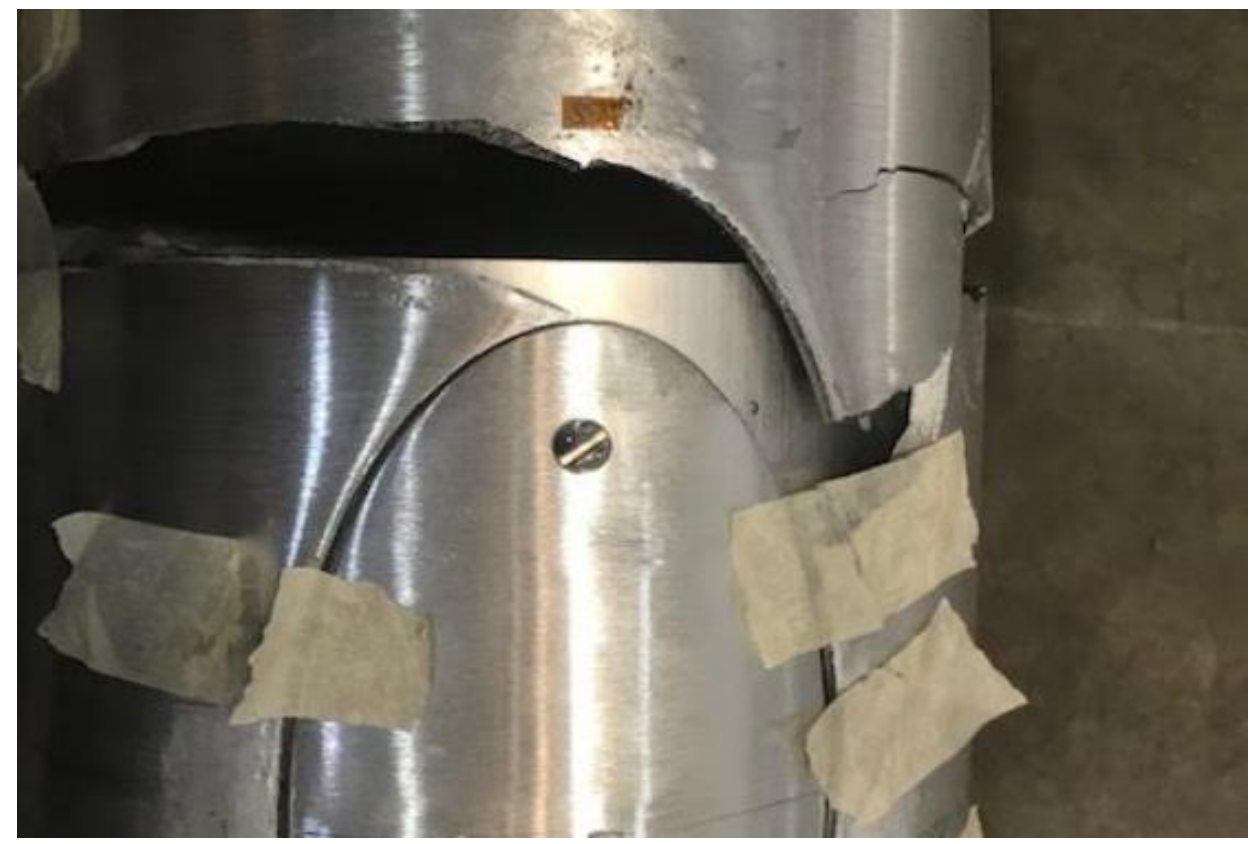

Fig. 12 Final failure

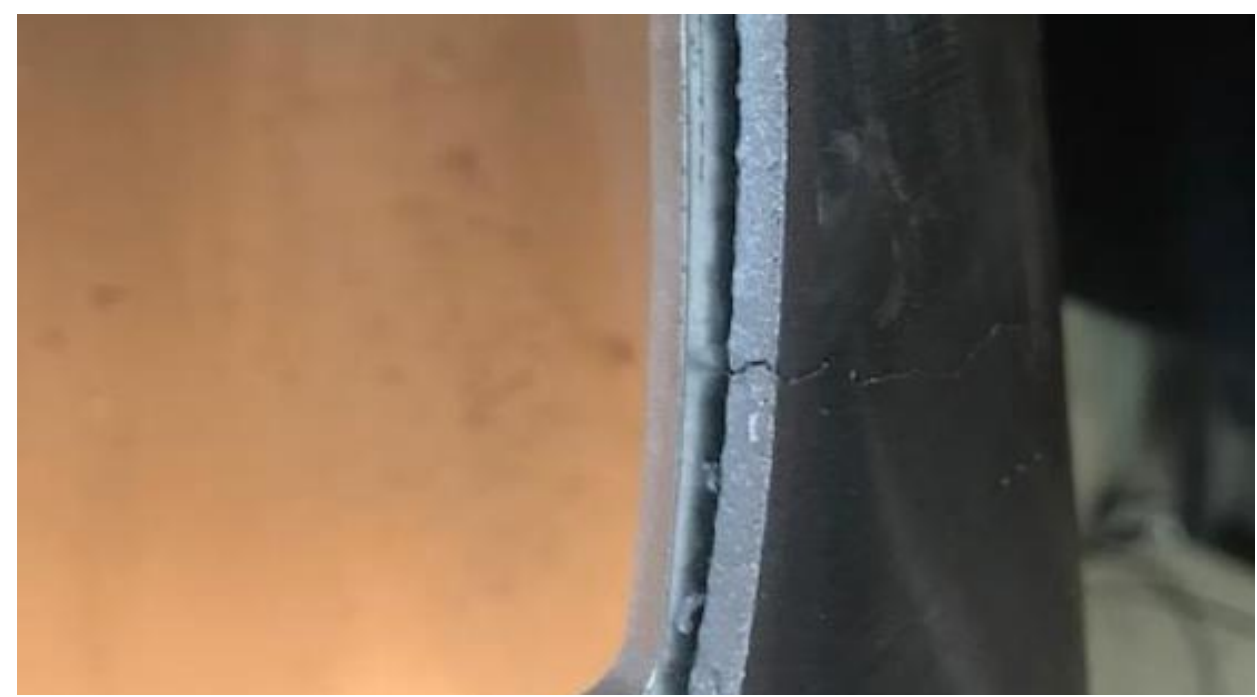

Fig. 13 Cracking in Pole Wall 


\section{Finite Element Modeling}

A finite element (FE) model was constructed of the three-point bending specimen to help understand the stress distribution around the hand-holes. The model was created to represent the geometry of the specimens as manufactured and to examine the local stresses associated with the flush hand-hole design as compared to the more typical handhole detail with reinforcement welded to the outside of the pole. Local stresses are generally mesh dependent. Finer mesh sizes usually increase stresses local to important geometric details, whereas a course mesh often results in a reduction in local stresses. Elements used in this model consisted of both tetrahedral and hexahedral element types. The mix of element types provided a fairly accurate model of the specimen and provided for reasonable run times. If the model had been constructed with hexahedral elements only, the open handholes would not have been meshed in a realistic manner. A full model consisting of tetrahedral elements would make nodal loading more complex than necessary. A global mesh size of 0.25 was used and the model consisted of 1,347,205 nodes. One hundred twenty-six nodes were used to apply the load, each with a concentrated force of $0.0558 \mathrm{~N}$ and was identical to the load used in a previous study and made for easy comparison. One hundred twenty-six nodes were used to represent each support and were restricted in three degrees of freedom and acted as the rollers at each end. Figure 14 depicts the mesh.

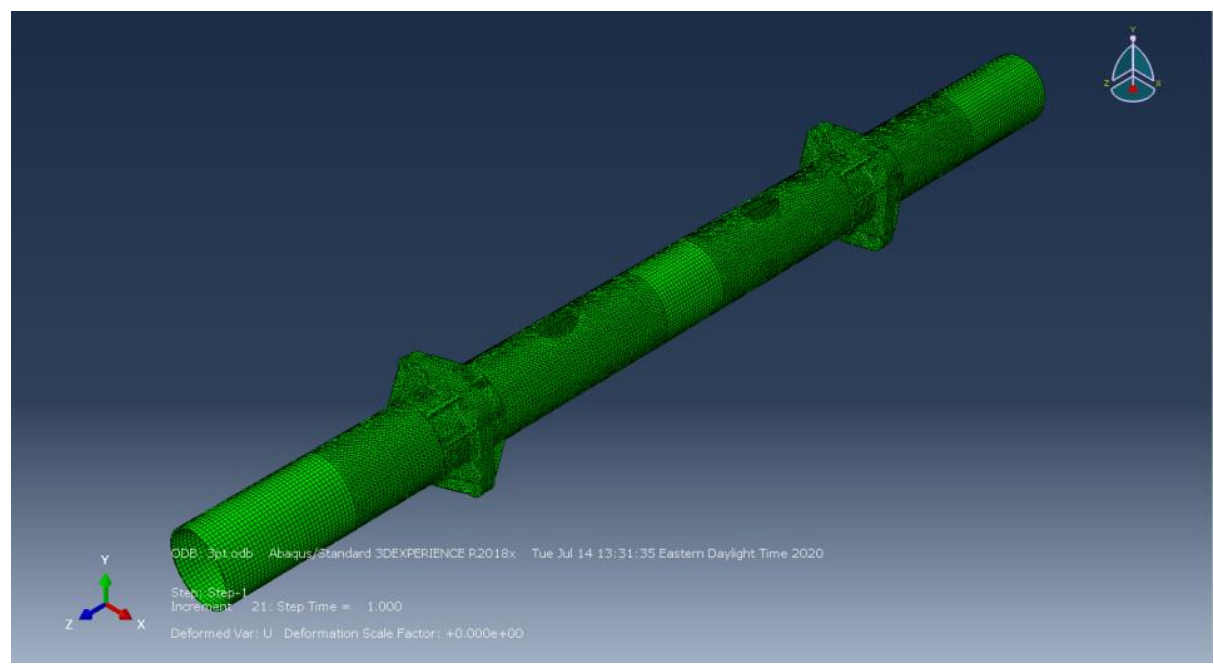

Fig. 14 Overall model

Stress "hot spots" indicate where fatigue cracking is likely to develop and where failure may occur. Figures 13-15 depict the stresses on the outside surface of the pole in $\mathrm{X}, \mathrm{Y}$, and $\mathrm{Z}$ directions respectively. The longitudinal stress corresponds to the $\mathrm{Z}$ axis and the transverse stress corresponds to the $\mathrm{X}$ axis. From Figure 13, there appears to be some concentration of stress around the reinforcement and at the corner of the reinforcement inside of the pole. Figure 14 shows how the stress formed around the reinforcement extrusion on the inside of the pole. Figure 15 depicts how the stress is transferred in the longitudinal direction. 


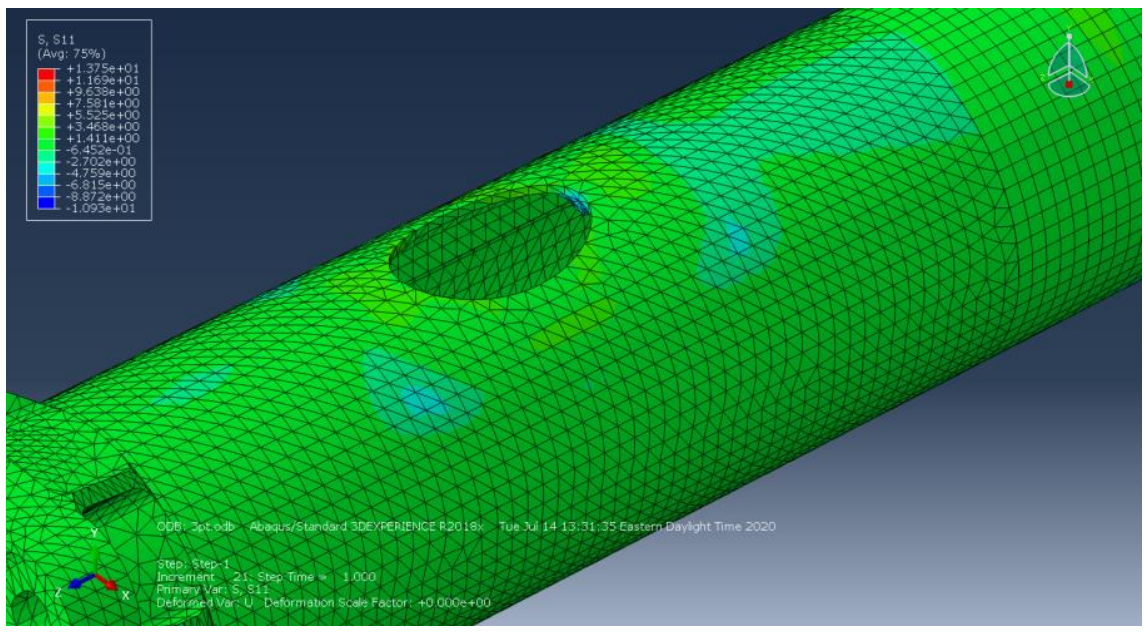

Fig. 13 Stress map in transverse direction

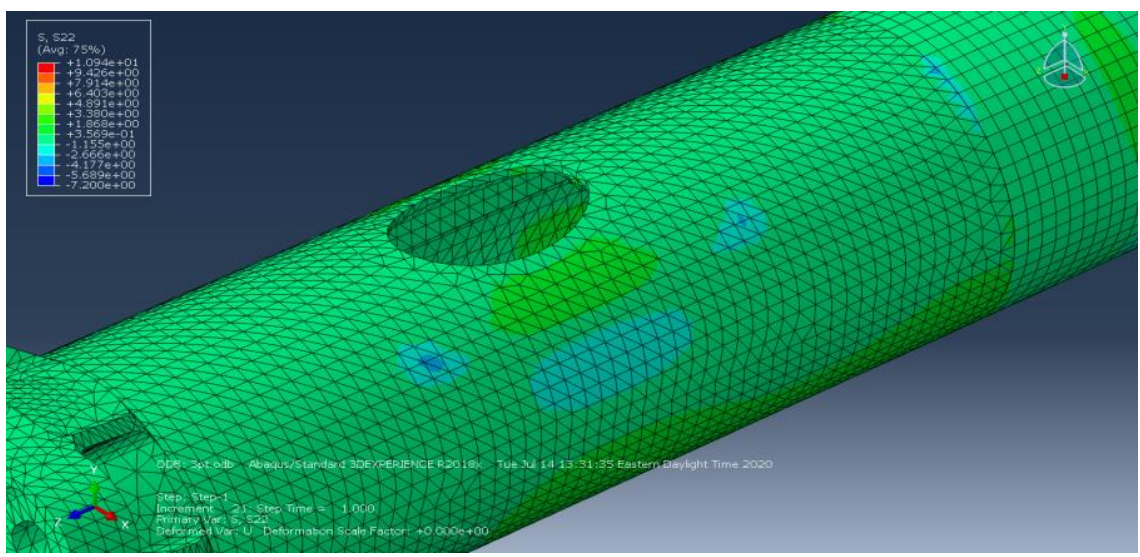

Fig.14 Stress map through the thickness of the pole

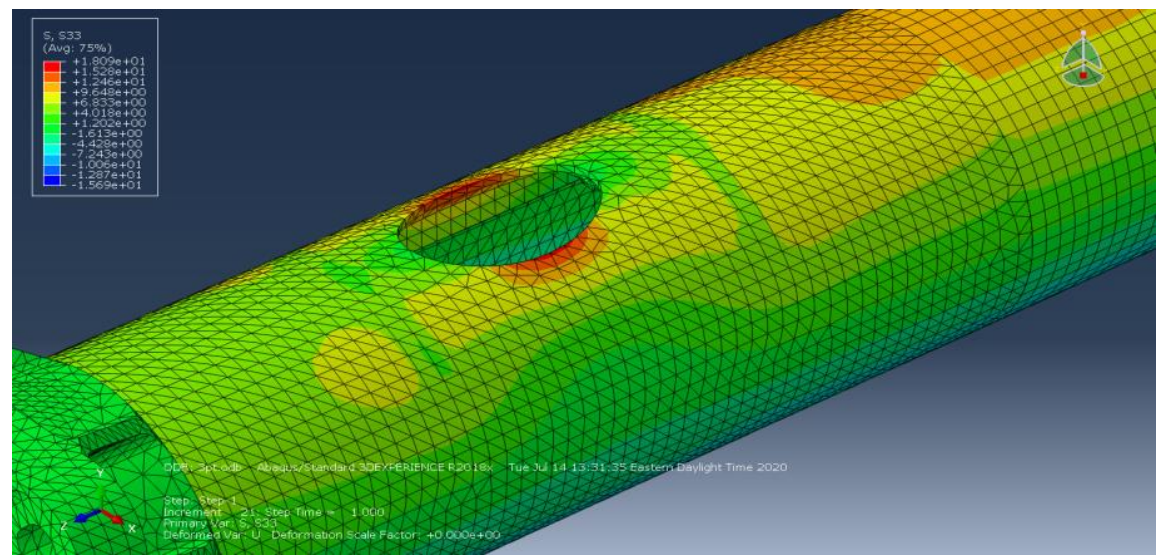

Fig. 15 Stress map in longitudinal direction 
Figures 16-18 depict the same stress maps as Figures 13-15 but show the stresses on the inside of the pole. What was most interesting about these images is that one can see how the stress collected around the ends of the extruded reinforcement even without the weld being modeled. This was typically the initial point of cracking.

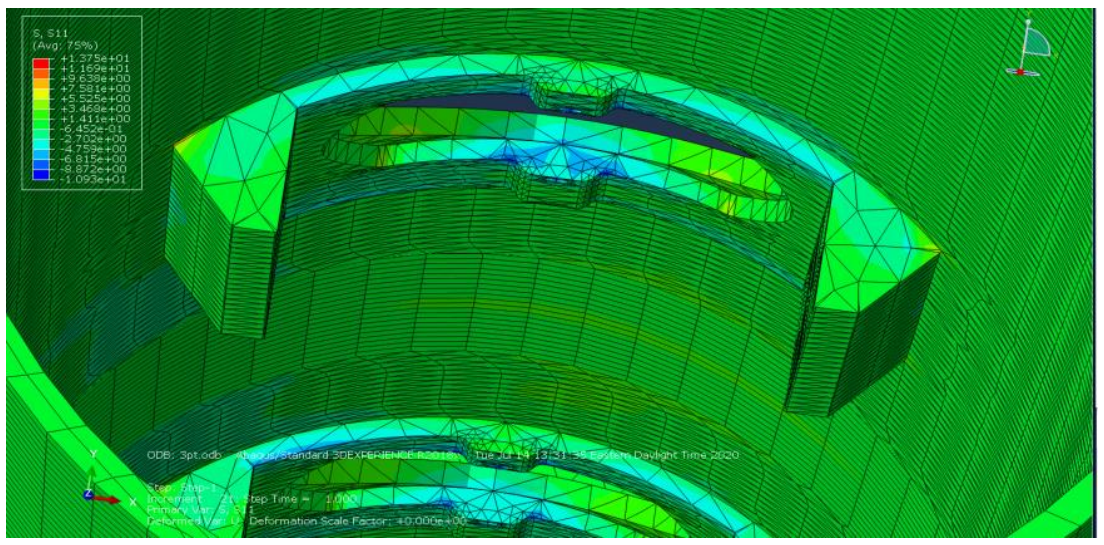

Fig. 16 Stress map in transverse direction inside pole

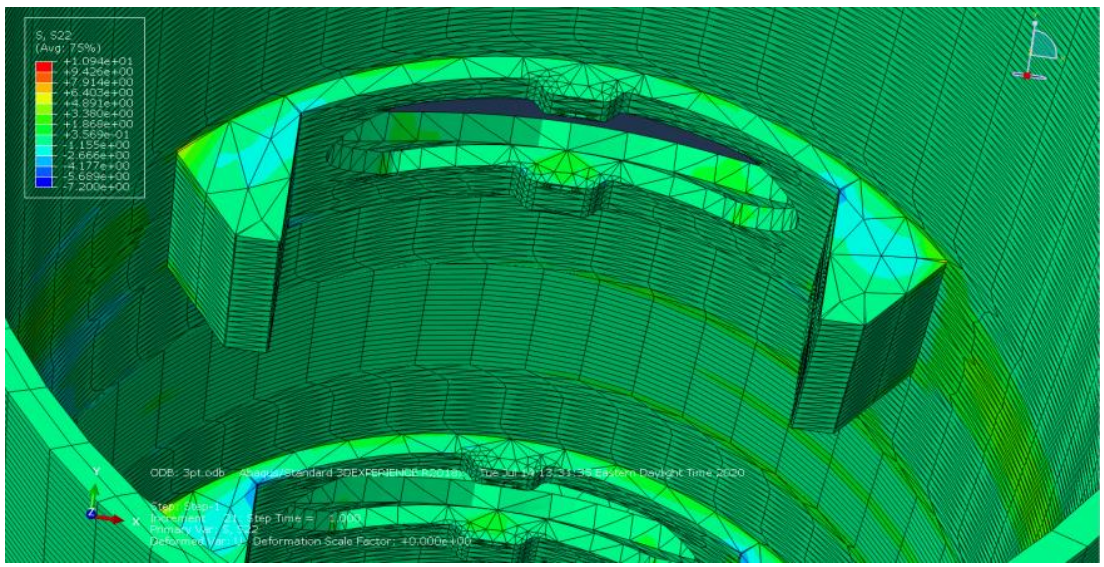

Fig. 17 Stress map through the thickness inside pole

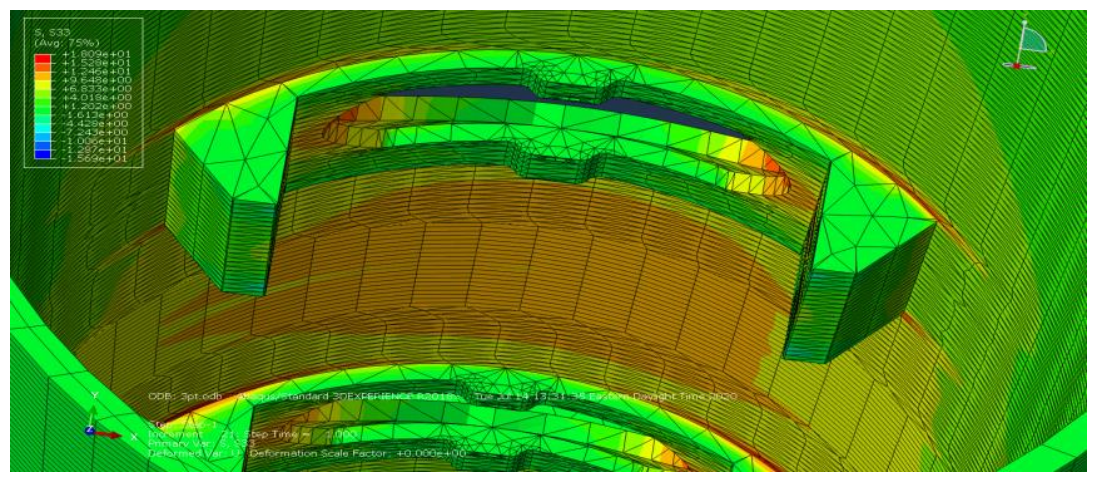

Fig. 18 Stress map in longitudinal direction inside pole 
In comparing the finite element results to a previous study, the change in detail affects the stress concentration around the hand-holes. Figure 19 shows the stresses in the longitudinal direction of the specimen with a cast insert joined to the outside of the pole. In this figure, the stress is most prevalent around "ends" of the cast insert whereas the flush inserts had a larger and more prevalent stress concentration on the inside of the pole near the corners of the reinforcement extrusion.

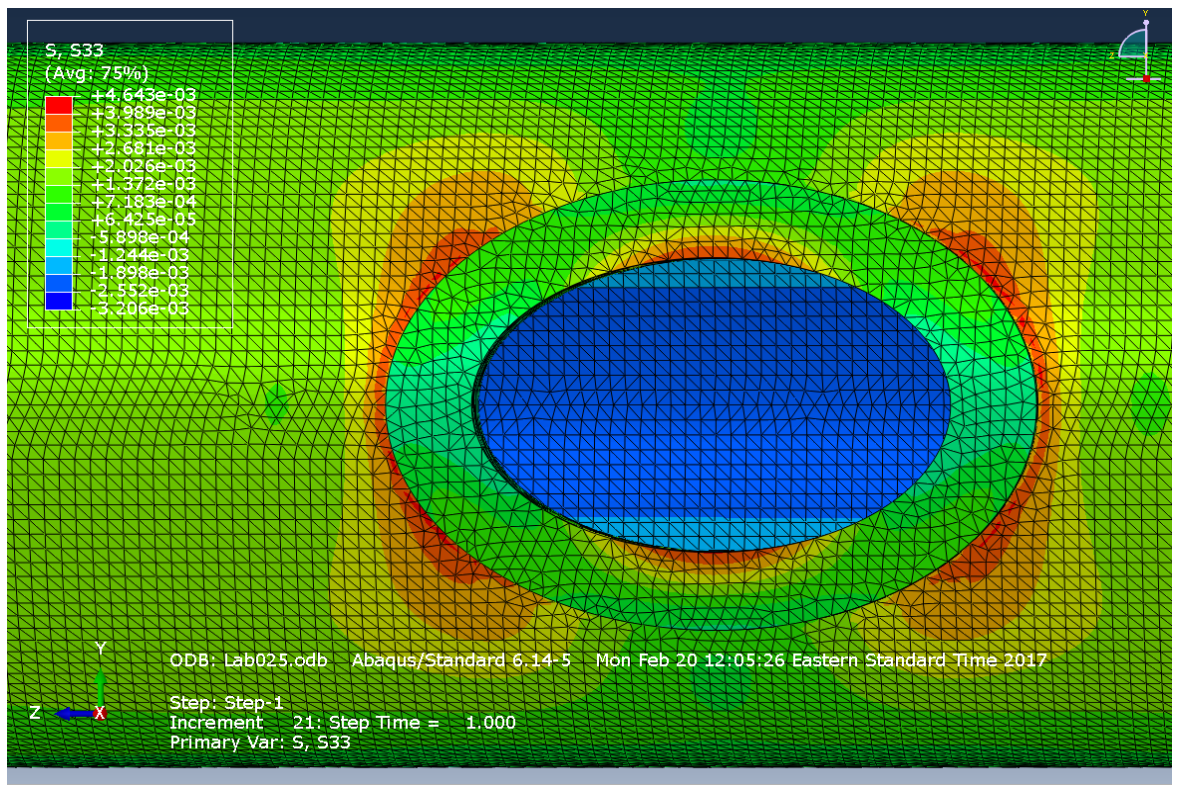

Fig. 19 Longitudinal stress map old study

\section{Conclusions}

Fatigue tests were conducted on aluminum light pole samples containing a welded flush hand-hole detail on the inside of the pole. The data collected shows the data being close to the "E detail" design S-N curve. It is important to note that lower bound is used to establish the design S-N curves. Additional test results would assist with evaluation of the data scatter and provide a better estimate of the lower bound, which would be expected to be lower than a category E detail. These test results were also compared to an older study that examined "typical" reinforced hand-hole details conducted at the University of Akron. In comparison, (Figure 8), the flush handhole details had significantly shorter fatigue lives than "typical" details that employed reinforcement joined to the outside of the pole.

Fatigue cracking of the flush details appeared abruptly, and the specimens failed shortly after a "crack" was visually observed. After further analysis it was determined that initial fatigue cracking occurred at the area on the inside of the pole where the fillet weld was terminated. In aluminum it is typical for weld terminations to contain shrink cracks if not properly "buttoned up" with additional weld metal. In this case, buttoning up of the termination is difficult with the detail on the inside of the pole. The fillet weld termination created an area that favored crack development.

A finite element model was created to show local stresses around the hand-hole in the flush design. The finite element model of the specimen with the flush detail was compared to the original model from the previous study of details with reinforcement joined to the outside of the pole. Examination of the images on both the outside and inside of the pole 
reveals how the detail termination on the inside of the pole negatively affects the stress concentration. In the case of the longitudinal stresses, there was a concentration of stress near the "corners" of the internal reinforcement even without the weld explicitly modeled. Addition of the weld would complicate the model as difficulties including shrink cracks would require many additional elements. An amendment to the welding process could be recommended in order to reduce the possibility of shrink cracking.

In general, it was found that the older design had longer fatigue life as compared to that of the flush detail.

\section{Acknowledgments}

The authors would like to convey their gratitude to HAPCO Company for manufacturing the sample, providing valuable discussion, and funding for the study.

\section{References}

[1] Murthy MVV, Rao KP, Rao AK. On stresses around an arbitrarily oriented crack in a cylindrical shell. Int J Solids Struct 1974; 10: 1243-1269. https://doi.org/10.1016/0020-7683(74)90071-7

[2] Durelli AJ, Parks VJ, Feng HC. Stresses around an elliptical hole in a finite plate subjected to axial loading. J Appl Mech 1966; 33: 192-195. https://doi.org/10.1115/1.3624979

[3] Aluminum Design Manual: Specification for Aluminum Structures. The Aluminum Association, Arlington, VA, USA; 2010.

[4] Fisher JW, Kulak GL, Smith IFC. A fatigue primer for structural engineers. National Steel Bridge Alliance: AISC; 1998.

[5] AASHTO (American Association of State Highway and Transportation Officials). Standard specifications for structural supports for highway signs, luminaires and traffic signals (LRFDLTS-1), Washington, DC, USA; 2015.

[6] Roy S, Park YC, Sause R, Fisher JW, Kaufmann EJ. Cost-effective connection details for highway sign, luminaire, and traffic signal structures. NCHRP 10-70 web-only Doc. 176, Transportation Research Board, Washington, DC, USA; 2011.

[7] Dexter RJ, Ricker NJ. Fatigue-resistant design of cantilevered signal, sign, and light supports, NCHRP Rep 469. Univ of Minnesota, Minneapolis, MN, USA; 2002.

[8] Menzemer C. Examination of several Mullica river bridge light poles, corresponding to J. Bowman, Hapco, USA; 2012

[9] Daneshkhah AR, Schlatter CR, Rusnak CR, Menzemer CC. Fatigue behavior of reinforced welded hand-holes in aluminum light poles. Engineering Structures and Materials Vol 188. https://doi.org/10.1016/i.engstruct.2019.03.013

[10] Rusnak CR. Fatigue behavior in reinforced electrical access holes in aluminum light pole support structures. Master's thesis, the University of Akron, Akron, OH, USA; 2019.

[11] Taghipoor H, Damghani Nouri M. Axial crushing and transverse bending responses of sandwich structures with lattice core. J Sandw Struct Mater [Internet]. 2018 Feb 26. https://doi.org/10.1177/1099636218761321

[12] Taghipoor H, Noori MD. Experimental and numerical study on energy absorption of lattice-core sandwich beam. Steel Compos Struct [Internet]. 2018;27(2):135-47

[13] Taghipoor H, Eyvazian A, Ghiaskar A, Praveen Kumar A, Magid Hamouda A, Gobbi M. Experimental and numerical study of lattice-core sandwich panels under low-speed impact. Mater Today Proc [Internet]. 2020 Mar;27(xxxx):1487-92. https://doi.org/10.1016/j.matpr.2020.03.001

[14] Hilty E, Menzemer C, Manigandan K, Srivatsan T. Influence of welding and heat treatment on microstructure, properties and fracture behavior of a wrought aluminum alloy. Emerg Mater Res 2014; 3:230-242. https://doi.org/10.1680/emr.14.00006 
[15] Schlatter CR. Fatigue behavior of the reinforced electrical access hole in aluminum light pole structures. Master's thesis, the University of Akron, Akron, OH, USA; 2017.

[16] The Aluminum Association. Aluminum Standards and Data 2017 Metric SI, USA; 2017

[17] Menzemer C, Srivatsan T.S. The effect of environment on fatigue crack growth behavior of aluminum alloy 5456. Materials, Science \& Engineering 1999. https://doi.org/10.1016/S0921-5093(99)00222-1

[18] The Aluminum Association. Specification for Aluminum Structures: Aluminum Design Manual (ADM) Washington, DC, USA; 2015. 